\title{
Defining and Describing Fruit Quality of Mango, its Development and Protection in Fruit Production
}

\section{Elliot Negros Madonsela*}

\section{Department of Crop Science, Faculty of Science, Tshwane University of Technology, South Africa}

*Corresponding Author: Elliot Negros Madonsela, Department of Crop Science, Faculty of Science, Tshwane University of Technology, South Africa.

Received: July 30, 2019; Published: August 08, 2019

DOI: $10.31080 /$ ASAG.2019.03.0603

\section{Introduction}

In this seminar the key concept was the fruit quality of mango and how that fruit quality was developed and protected in the general fruit production. Materials and method for this study were scientific texts and literature review. Texts used have gone under peer reviews for validation and accuracy. The fruit of interest in this study is mango. Mango also scientifically known as Mangifera Indica which originates from the India/Burmese border region. The region is said to be a subtropical monsoon area in the Himalayan foothills [1]. Mango belongs to the Anacardiaceae family of which contains many other valuable trees such as cashew, pistachio nuts and marula. The genus Mangifera has many species with edible fruit but mango is the only species that is grown commercially on a large scale, that is according to W. Schroeder [1]. The mango tree is believed to have evolved as a canopy layer species in the tropical rainforest of south and southeast Asia [2]. Mature trees can go to a height of $30 \mathrm{~m}$ and can survive for more than a 100years. The root system consists of a long vigorous tap root and abundant surface feeder roots. The plant is an arborescent evergreen tree. It has simple leaves that alternate, oblongovate, to oblong lanceolate leaves that are spirally a rranged and produced in flushes [2]. Leaves may be up to $450 \mathrm{~mm}$ in length and $130 \mathrm{~mm}$ width, when mature leaves are glossy dark green but when young they are yellow-green or brown-red [1]. Its flowers are borne on terminal pyramid panicles, glabrous or in pubescent form. The inflorescence is rigid and erect and is widely branched usually densely flowered with hundreds of small flowers with a diameter of $5-10 \mathrm{~mm}$. the flowers are small and monoecious and polygamous. Both male and perfect flowers are found on a single inflorescence, the pistol aborts in male flowers. The ratio of male to perfect flowers is greatly dependent to environmental factors and cultural factors. The flowers have four to five sepals that are ovate to ovate oblong and so highly pubescent. There's four to five petals that are oblong to ovoid to lanceolate and also thinly pubescent. Floral disc is $4-5$ lobed, fleshy and large and located above the base of the petals. Five large, fleshy nectaries form a five-lobed receptacle. Although there are multiple stamens only a few are fertile and the remainder are sterile staminodes that are surmounted by a small gland, filaments arise from nectarie lobes and stamens are central. Cross-pollination is believed to be done by flies [2]. The mango fruit is a large, fleshy drupe, containing edible mesocarp of varying thickness. It is resinous and highly variable when it comes to shape and size. Chlorophyll, carotenes, anthocyanins and xanthopylls are all present in the fruit [2]. The fruit morphology is greatly dependent on the cultivar, whether how big or small, dense or soft or even fibrous, less fibrous. There are polyembryonic seed cultivars and monoembryonic seed cutlivars [1]. The seed of mango is solitary, large and flat, ovoid oblong and surrounded by the fibrous endocarp at maturity. The testa is thin and papery. The seeds are not labyrinthine. The production of mango will further be discussed in this seminar. The objectives of this seminar was to look at quality and whether or not it is linked to production, environment or handling. Or to find out what are the influencers of mango quality.

\section{Describing fruit quality}

Quality in essential is the degree of excellence or superiority of fresh fruits and their products, this is a combination of attributes, properties or characteristics that give each commodity value in terms of human food. The prospective importance of each quality component depends on the commodity's intended use. Whether it be processed goods or fresh produce. It varies among producers, handlers and consumers. For producers a given commodity must have high yield and good appearance, easy to harvest and must withstand long-distance shipping to markets. Appearance quality, firmness and shelf life are important as a quality measure for the wholesale and retail marketers (handlers). Consumers judge quality of fresh fruits on the basis of appearance and firmness at the time of initial purchase. Subsequent purchases depend on the consumer's satisfaction in terms of flavor and eating quality of the product. Consumers are also concerned about the nutritional quality of fresh fruits of which are not only colourful and flavourful components of our diet, but are a good source of energy, vitamins, minerals, dietary fibres and many bioactive compounds that enhance human health (Kader,1999. Chapter 1). Mango fruit 
contain amino acids, carbohydrates, fatty acids, minerals, organic acids, proteins and vitamins. During the ripening process the fruit is initially acidic, astringent and rich in ascorbic acid or otherwise known as vitamin C. Ripe mangoes have moderate levels of vitamin C but are fairly rich in provitamin A, vitamin B1 and B2. The mango pulp contains as much vitamin a as butter but vitamin $\mathrm{D}$ is not that significant in quantity [2]. Maturity is a majorly critical factor when observing or determining quality, it is used in deciding when a commodity should be harvested to provide some marketing flexibility and to ensure the attainment of acceptable eating quality to the consumer. Maturity at harvest is the most important factor that determines storage-life and final fruit quality. Immature fruits are more subject to shriveling and mechanical damage and are inferior quality when ripe. Over-ripe fruits become soft and mealy. Basically any fruit picked too early or too late in its season is more susceptible to physiological disorders and has shorter shelf-life than fruits picked at proper maturity (Kadar.,1999.).

\section{Development and protection}

\section{Climatic requirements}

Mango can tolerate a wide range and variations in temperature and grows well in both tropical and subtropical areas. The optimum temperature for the production of mangoes is between 8 and $26^{\circ} \mathrm{C}$. Temperatures lower than that may cause low yield or no yield at all. And temperatures below zero cause dieback of the tree. The tree is not resistant to frost. A mean of $8^{\circ} \mathrm{C}$ minimum temperature per month is the absolute limit for production in winter. Although mature trees can survive low temperatures fruiting will not happen as low temperatures damage flowers and delay flowering. Low temperatures also have adverse effects on fertilisations especially during pollination. It is generally accepted that there is a cessation of pollen tube growth, fertilization, and embryo development at temperatures below $12^{\circ} \mathrm{C}$, this results in a known event called "mule fruit" which means small fruit in mango. Specific temperature requirements differ from cultivar to cultivar. Mangoes grow well in areas of high temperatures. A monthly mean of above $27^{\circ} \mathrm{C}$ is favourable but anything above $36^{\circ} \mathrm{C}$ on average monthly is bad and can cause sunburn on fruits if tree suffered from hampered growth or leaf drop [3]. Looking at this means that temperature and light exposure can have a great effect on the quality of the fruit especially when it comes to appearance cosmetically and size.

Mango usually grows in areas with an annual rainfall of 250 to $2500 \mathrm{~mm}$. in the tropical areas vegetative growth is very vigorous and yields are low this is due to high rainfall. This gave rise to the assumption that winter irrigation should be suspended to initiate flower formation. In summer rainfall areas winter irrigation should continue to prevent adverse effects on tree growth, flowering and fruit-set. The fruits and flowers are very sensitive to fungal diseases that develop in moist conditions. To reduce disease incidence it is well advised that mangoes be grown where relative humidity and rainfall are low when flowering a and fruit development take place, in such areas irrigation must be done regularly and very correctly to prevent stress during the growing period [3]. Moisture control is then a very important factor that affects the timing in fruit formation which will evidently affect the quality of the end product.

\section{Soil requirements}

Mangoes are reported to be tolerant to many soil types, trees grow vigorously in deep fertile and moderately acid to neutral $\mathrm{pH}$. Basically loam type soils but tolerate infertile sands, volcanic ash and limestone based soils. Soils excessively drained or periodically flooded, soils with pH of $4-7$ or 8.5. Mangoes are sensitive to saline and sodic soil conditions and proper irrigation practices are needed along with a salt-tolerant rootstock for any kind of production [2]. This plant prefers soils that are well drained. It performs best when planted on a slope which enables the run-off of excess water and thus prevents water-logging. Depressions or basins are usually poorly drained and planting in such sites should be avoided because oversaturated soils cause roots to become black and desiccated due to lack of aeration. Wilting may follow upper body parts of the tree. Soil with impermeable layers include plinthic horizons which don't favour mango growth. However mango cannot thrive on very steep slopes since excessive drainage could lead to water shortage and soil erosion. Mango grows well in soils with an unimpeded depth of $1 \mathrm{~m}$ or more. But soil depth of up to $750 \mathrm{~mm}$ can be managed for good production provided the layer limiting further root development doesn't restrict drainage, irrigation schedule would have to be custom. The ideal soil texture for mango cultivation is sandy loam or loam with clay content of about $15 \%$ to $25 \%$ but soils with $50 \%$ clay are manageable. If the clay content is above $50 \%$ plant root penetration will be impeded and waterlogging may occur. Trees planted in sandy soils have been known to produce fruit of an inferior quality, watery and tasteless. The ideal soil structure is firstly loose, brittle and crumbly. Compact or strongly developed soil structures obstruct infiltration and root penetration [4].

Water requirements are dependent on the soil available moisture and drainage. This is why farmers have been known to suspend irrigation a few months before flowering to limit vegetative growth that favours high moisture. Both fruit-drop, size and the quality of mango fruit seems to be influenced by water availability at certain times [4]. Chemical requirements are also dependent on soil conditions specifically pH levels. According R.A. Abercrombie [4] at lower or higher values of 6 to $7.2 \mathrm{pH}$ trees may suffer from trace element, phosphate or potassium deficiencies. 


\section{Protection}

Discussed in this part are the organisms that affect mango development and growth, whether they macro-organisms in the form of pests or micro-organisms in the form of diseases. Only commercially detrimental organisms are looked at. Mango scale insect infests the branches, leaves and fruit. The crawlers move from the mature female to the different parts of the tree, the y can also spread by wind and birds. The crawlers develop into male or female bug. All have whitish scale covers, females are circular, males are oblong. These insects extract sap from the plant which causes yellow or dead spots on the leaves and yellowish red spots on fruit. Severe infestation can cause leaf drop. The mango scale is controlled biologically by insects that feed on it or parasitise the scale and by chemical spraying. Fruit flies attack the fruit when they start colouring or ripening. The fly lays eggs inside the fruit, maggots hatch and feed on the fruit flesh. The fruit flesh becomes soft then brown eventually rotting. To prevent infestation, tree must be sprayed with fenthion. The spray must be aimed a fruit and must be applied weeks before harvest with enough time for the safety period to laps before harvest. The coconut bug or otherwise known as the stink bug is approximately $15 \mathrm{~mm}$ in length, rusty coloured with dark wingtips. These insects can fly. They start feeding and extracting sap from the fruit while the fruit is still small.

Even immature nymphs that cannot fly cause damage to fruits. A dark sunken lesion develops on the fruit where it has been damaged. Damaged fruit can turn greyish brown, shrink and drop from the tree. No chemical has been registered for the control of this pest. Chemicals used to control fruit flies have been known to work up to a certain point [3].

Diseases affecting mango. Powdery mildew which is a fungus that attacks the blossoms of young leaves and fruit. The first symptom is a white, powdery growth on the infected part. The disease is very serious during wet season. Various fungicides are effective against this pathogen especially if they are sulphur or copper based chemicals. Bacterial black spot disease is encouraged by wet conditions and is extremely difficult to control. The symptoms on the leaves are small, dark brown, angular lesions. Lesions can appear on small fruit. Lesions on fruit enlarge as the fruit grows and crack open releasing a gummy exudate. The common control is copper oxychloride solution, it has to be used repeatedly during fruit-set and wet conditions. The bacterial black spot control measures seem to work even on Anthracnose. Anthracnose is a fungal disease that causes brown lesions on mature fruit and often appears in the form of tear stains on the fruit where water has run down. Infection can occur anytime during development, disease can also be dormant so fruit protection must be done from early stage. Copper spraying is recommended [3].

\section{Production}

The production of mango starts by orchard planning, having considered the requirements of the plant one must do a proper site selection. Orchard site must be slightly slope to allow drainage because waterlogging affects yield and may cause tree death, good climate or weather to simulate tropical or subtropical conditions, source of water whether production is rainfed or done under irrigation. Irrigation types considered for input cost and effectiveness, whether overhead irrigation or dripper irrigation. Land preparation is considered in terms of ploughing, soil compaction and soil chemical make if there be a need for soil correction or not. Of which soil correction can be impossible in extreme cases. Soil preparation may require soil sampling according to Smith (1992) soil should be sampled at least 9 months before planting but 12 to 24 months gives farmer ample time for major preparations.

The success of the orchard not only depends on the land preparation but on the quality of nursery trees. When purchasing trees it should be from a reputable nursery with more than 10years experience, the prospective buyer should visit the nursery to examine the trees and see if they are up to standard. Foliage, flowers, internodes, graft-union and soil mixture container including root systems should be inspected each time during growth period before planting. The foliage of a nursery tree should have a glossy, green colour, giving a general appearance of good health. Deformed discoloured leaves mean ill practices by nursery. If the trees are flowering in the nursery make sure that blossom malformation symptoms are not present. Even after planting symptoms should be monitored, infected trees should be removed and burnt. Long internode are a good indication of a vigorous healthy tree. Plants with compressed internodes indicate zinc deficiency. And abnormal graft-union indicates incompatibility, a poor rootstock or a diseased scion. First-grade trees have a few leaves on the rootstock below graft union. Trees should be uniform and grafted at the same height. Bark cracking means mono-embryonic seedlings have been used. Soil mixture and container play a role in high quality trees, a mixture with a high clay content limits drainage and limits root respiration and growth. Small containers result in trees being prematurely root bound which will affect it after transplanting in the orchard. The growth medium should be well rotted compost, sand and loam. Containers should be atleast 10L [5].

Mango should be planted late spring to early summer and late summer to early autumn. Planting during spring is not advised because of hot dry weather. In ploughed soils large planting holes are not needed. In unprepared soils holes must be $750 \mathrm{~mm}$ by $750 \mathrm{~mm}$, and should be dug 2 months before planting to allow the weathering of the hole walls which makes for easier root penetration. Trees should be well hardened-off before transplanting and not transplanted during flush periods. Before planting the hole should be 
filled to a depth slightly less than the height of container to accommodate root soil complex. Care should be taken not to disturb the roots when planting. The hole should be filled with the remaining topsoil and a basing made around the plant. Watering should be done immediately to allow roots to settle. New planting must be irrigated weekly to limit plant stress. If roots have been disturbed shade and mulching will help with development (Schroeder and Snyman, 1991)

For the fertilization of mango the most important elements are nitrogen $(\mathrm{N})$ and potassium $(\mathrm{K})$. Young trees should not be fertilized during the first year after transplanting has been done. As the tree gets older fertilization must correlate with irrigation schedule. Fertilizers must be applied in the drip areas of the tree and not on or against the trunk. Fertilization times must be split between early spring and late summer. To ensure soil doesn't become too acidic, dolomitic agricultural lime can be applied at $2 \mathrm{~kg}$ per tree every second year [3]. With all this taken into account the orchard can then be established. And management of the orchard will require proper irrigation management, timely fertilization and constant scouting for infection of disease or infestation by pests. Orchard sanitation measure must always be taken into account and used. Trees with diseases must be cut down and burnt to eradicate the pathogen and limit epidemic which can destroy the whole orchard. Orchard floor must be kept clean to limit possible incubation and spread of disease $[6,7]$.

\section{Conclusion}

Results obtained from the study strongly suggest that defining quality is not uniform, moreover the quality of mango cannot be determined by one factor or reliant on one definition. The climatic requirements can affect the quality of the mature fruit and the cosmetic appearance, and the soil requirements affect the taste of the fruit. Rainfall or moisture availability affects the timing of fruit formation and size. The pests and diseases discussed here have shown to affect the physiological structure of the fruit. All these show quality being affected at different stages of development. Hence in production all these factors are taken into account and an orchard is established with the final fruit quality in mind starting with the seedling quality which is carefully taken care of until it has to face the elements. Basically a good seedling/plantling coupled with good farming practices ensures the finest possible quality that a grower can attain. Generally every practice in mango cultivation has a direct and indirect influence on the final outcome.

Volume 3 Issue 9 September 2019

(C) All rights are reserved by Elliot Negros Madonsela. 